\title{
Determining the Recurrence of Diabetic Patients Recovery Time in Benishangul-Gumuz Hospitals, Ethiopia
}

Endalkachew ( $\nabla$ w1endalk@gmail.com )

Assosa Univeristy

Zelalem

Assosa Univeristy

\section{Research Article}

Keywords: Diabetic Patients, Recovery Time, Recurrent Event, Shared Frailty Model

Posted Date: March 2nd, 2022

DOI: https://doi.org/10.21203/rs.3.rs-1407240/v2

License: (c) (1) This work is licensed under a Creative Commons Attribution 4.0 International License.

Read Full License 


\title{
Determining the Recurrence of Diabetic Patients Recovery Time in Benishangul-Gumuz
}

Hospitals, Ethiopia

Endalkachew Abebe', Zelalem Birku²

${ }^{1}$ Department of Statistics, College of Natural \& Computational Sciences, Assosa Univeristy, Assosa, Ethiopia

${ }^{2}$ Department of Mid-wifer, College of Health Sciences, Assosa Univeristy, Assosa, Ethiopia

\begin{abstract}
Diabetes is a chronic, metabolic disease characterized by elevated levels of blood glucose (or blood sugar). About $90 \%$ of people with diabetes around the world have type II diabetes. It is the main global health issues and burden as well with serious health complications including heart disease, blindness, kidney failure, and lower-extremity amputations. In middle- and low-income countries the prevalence of diabetes has been rising more rapidly and needs great attention. The data from such case has been considered as recurrent event data and correlation between events should be taken into account in the analysis. Thus, the aim of the study was to identify risk factors for recurrence of diabetic patients recovery time in Benishangul-Gumuz hospitals (Assosa, Pawi and Wonbera hospital), Ethiopia. A retrospective study has been applied to obtain data on the recurrence of diabetic patient's recovery time in Benishangul-Gumuz hospitals, Ethiopia, from September 1, 2019 to September 1, 2021. Kaplan-Meier plot (s) and Log-rank test were used for comparison of patients recovery time from diabetes; Standard Cox-PH and Shared Frailty model were used to identify factors significantly affect the recovery time of diabetic patients, using $R$ version 4.1.1 for data analysis. Of the total diabetic patients in this study 61.87 $\%$ experienced recurrence of diabetic. The estimated median recovery time of diabetic patient's was 6 months. The Shared Log-normal Frailty model was chosen to be best fit for this data set, based on Likelihood Cross-Validation value. Family history, other medical history and Systolic Blood Pressure of patients were significantly affected the recovery time of diabetic patient's.
\end{abstract}

Keywords: Diabetic Patients, Recovery Time, Recurrent Event, Shared Frailty Model 


\section{Background of the Study}

Diabetes is a chronic metabolic disease characterized by elevated levels of blood glucose (or blood sugar). It is due to either the pancreas, an organ that lies near the stomach, making a hormone called insulin to help glucose get into the cells of our body, not producing enough insulin, or the cells of the body not responding properly to the insulin produced (WHO, 2021). Diabetes leads over time to serious damage to the heart, blood vessels, eyes, kidneys, and nerves (GBD, 2015; Hossam, 2014; WHO, 2021). There are three main types of diabetes: type 1, type 2, and gestational diabetes (diabetes while pregnant). Type 1 diabetes is characterized by a lack of insulin production and without daily administration of insulin it is rapidly fatal. The majority of type 1 diabetes occurs in children and adolescents. Type 2 diabetes is the most common type of diabetes, which occur in adults and results from the body's ineffective use of insulin. Approximately $10 \%$ of diabetic patients have type I diabetes and $90 \%$ of diabetic patients have type II diabetes. Gestational diabetes is hyperglycemia with blood glucose values above normal but below those diagnostic of diabetes. It occurs during pregnancy and women with this type of diabetes are at an increased risk of complications during pregnancy and at delivery. These women and possibly their children are also at increased risk of type 2 diabetes in the future. Gestational diabetes is diagnosed through prenatal screening, rather than through reported symptoms (IDF, 2021; WHO, 2021).

Diabetes is the main global health issue and a burden as well. About 422 million people worldwide have diabetes, the majority living in low-and middle-income countries, and 1.5 million deaths are directly attributed to diabetes each year. Both the number of cases and the prevalence of diabetes have been steadily increasing over the past few decades (WHO, 2021). In 2021, diabetes was the direct cause of 6.7 million deaths (IDF, 2021) and in 2019, 48\% of all deaths due to diabetes occurred before the age of 70 years (WHO, 2021). In middle- and lowincome countries, the prevalence of diabetes has been rising more rapidly and an estimated 416,000 deaths occur in 2021. Now a day, diabetes has emanated and emerged as an important clinical, public health, and economic problem throughout the world including developing countries. Ethiopia is one of the developing countries working with complications of diabetes like: substantial economic loss in people, health systems, and national economies through direct 
medical costs and loss of work (IDF, 2021). However, due to limited resources and its prevalence growing most rapidly, diabetes is worrying in the country (Dereje et al., 2020), diabetes needs a major focus in the country; unless when diabetes is not well managed, acute complications are a significant contributor to mortality, costs and poor quality of life (AMECA, 2015; Thomas et al., 2015).

The most common risk factors of diabetes are: age, sex, weight (Abiyot et al., 2014), regimen (Assaye, Bizuwork and Solomon, 2021), family history (InterAct Consortium: Scott et al., 2013), other medical history (Leon and Maddox, 2015) and Blood Pressure (Emdin et al., 2015).

The researchers are using logistic regression to identify risk factors for the occurrence of diabetes (Ambachew et al., 2015; Gizaw et al., 2015; Nshisso et al., 2012; Zekewos et al., 2018). However, such data can be more explored using survival models such as: standard Cox-PH, Shared Gamma Frailty, and Shared Log-normal Frailty models. Therefore, the overall aim of this study was to identify risk factors for recurrence of diabetic patients recovery time in Benishangul-Gumuz hospitals (Assosa, Pawi and Wombera hospital), Ethiopia using the data taken from diabetic patients during follow-up time from September 1, 2019 to September 1, 2021.

\section{Data and Methodology}

\section{Study Area}

The study was conducted at Benishangul-Gumuz hospitals (Assosa, Pawi and Wombera hospital). Benishangul-Gumuz hospitals are the hospitals found in Benishangul-Gumuz Regional State; in which the region is one of the nine regional states established in 1994 by the constitution of Ethiopia. Assosa hospital is found in Assosa town; Pawi and Wombera hospitals are found in Metekel zone, Benishangul-Gumuz region, Ethiopia. Assosa, thecapital city of the region, and Metekel zone are located in the northwestern part of Ethiopia, with $667 \mathrm{~km}$ and 792 $\mathrm{km}$ distance from Addis Ababa, Ethiopia, respectively. The hospitals have different cases for CNCDs and serves as the biggest referral hospital in the region.

\section{Study Population}

A retrospective study has been applied to obtain data on recurrence of diabetic patients in Benishangul-Gumuz hospitals (Assosa, Pawi and Wombera hospital). The population of this 
study was all diabetic patients go for treatment to Benishangul-Gumuz hospital for two years starting from September 1, 2019 to September 1, 2021. The data has been carefully reviewed from the registration log book and patients' registration card; any inadequate information encountered was checked from the file and excluded from analysis if proven to be inadequate. Thus, the data has been collected from patient follow-up records based on the variables in the study.

\section{Inclusion and Exclusion Criteria}

Inclusion Criteria: - All diabetic patients who have treatment follow-up in the hospital with full information including study variables eligible for the study are included in the study.

Exclusion criteria: - Gestational diabetes patients are not included in the study.

\section{Data Collection Procedure}

Ethical permission has been obtained from the Research Ethics Review Board of Assosa University. Then secondary data has been taken for the recurrence of diabetic patient's recovery time from patient card in the hospital by data collectors. The data collector in each hospital has been collecting the data after they took one day training on the objective and relevance of the study, how to gather the appropriate information, procedures of data collection techniques, and the whole contents of the interview. The researcher monitored the overall data collection process during the data collection period.

\section{Variables in the Study}

The outcome variable in this study was the time to recovery of diabetic patients. Time to recovery (might be one time, two times, or more than two times) means the time until patients come to normal fasting blood sugar levels for recurrent time in the follow-up period, according to WHO scale $(80-130 \mathrm{mg} / \mathrm{dl})$ and under $180 \mathrm{mg} / \mathrm{dl}$ for two hours after starting a meal. Patient's recovery from diabetes is an event of interest.

The covariates/predictors considered in this study were age $(<30,30-50,>50)$ in years, sex (female, male), educational status (uneducated, educated), marital status (single, married, divorced, widowed), employment status (unemployed, employee), family history (no, yes), other medical history (no, yes), regimen (oral Agents, insulin agents, oral and insulin agents), 
types of diabetes (T1D, T2D), specific drug used (Doanied, HCT, Metformin, Monotend, Lute, Regular, oral), Systolic Blood Pressure (low, normal, high) in mm/Hg, Diastolic Blood Pressure (low, normal, high) in $\mathrm{mm} / \mathrm{Hg}$ and weight (underweight, normal, overweight, obesity) in $\mathrm{Kg}$.

\section{Operational Definition of some covariates}

Regimen Group: - Diabetic patients were classified into regimen groups according to the medication they took in follow-up time as:-

Oral Agents Only : - all are administered orally in diabetic patients.

Insulin Agents Only: - is provided in a constant proportion to remove excess glucose from the blood, which otherwise would be toxic. It is given by injecting patients with the dose level ordered by the physician.

Both Oral and Insulin agents: - is another regimen group when patients are ordered to take both oral and insulin agents at the same time in the follow-up period.

Blood Pressure (BP) in ( $\mathbf{m m} / \mathbf{H g})$ : - measures the pressure in blood vessels of diabetic patients. It can be classified as Systolic and Diastolic Blood Pressure.

Family History of Diabetes: - having a family who had Diabetic Disease or not.

Other Medical History: - Whether the patients have other medical history before enrollment into a chronic follow-up clinic as a diabetic patient.

\section{Methods of Statistical Analysis}

\section{Descriptive Statistics}

The description of survival data utilizes non-parametric methods to compare the survival functions of two or more groups and Kaplan-Meier plot(s) would be employed for this purpose (Kaplan and Meier, 1958). The frequency distribution table was also used to summarize the data obtained from diabetic patients based on the study variables in Benishangul-Gumuz hospitals, Ethiopia.

\section{Survival Data Analysis}

Survival analysis is a statistical analytic method used for modeling and analyzing data that have a principal end point - the time until an event occurs. It considers a key analytical problem of 
censoring that occurs when some information about individual survival time is known, but not the exact survival time (Aalen, 2008). The censoring assumed to occur in this study is right censoring, meaning to say the true observed event is at the right of censoring time.

\section{Standard Cox Proportional Hazard Model}

The most frequently applied analysis method for recurrent data is the model by Andersen and Gill (1983), which is based on the common Cox-PH model (Cox, 1972). The Andersen-Gill model assumes independence between all observed event times irrespective whether these event times correspond to the same/different patients. According to Kleinbaum and Klein (2011), modeling recurrent survival data can be carried out using a Cox-PH model with the data layout constructed so that each subject has a line of data corresponding to each recurrent event. The assumption of Cox-PH model were checked by test of correlation (rho) and global test. The assumption is valid using test correlation (rho) and global test if the test result is insignificant (Grambsch and Therneau, 1994).

\section{Shared Frailty Model}

The Shared Frailty model is extended by Pickels et al. (1994) and Yashin et al. (1995) to allow unobserved heterogeneity that occurs because some observations are more prone to failure, and therefore more "Frail" than others in a data set. It may also use for modeling the degree of correlation within groups. Among different models: Shared Gamma Frailty model and Shared Log-normal Frailty model were used to model the data. The expectation-maximization (EM) algorithm and the penalized likelihood approach were used to estimate parameters in the models (Duchateau and Janssen, 2008). An approximate likelihood cross-validation criterion (LCV), approximately equivalent to Akaike's criterion, is used to check the goodness of fit for Cox and Frailty models (Gray RJ., 1992). Lower values of LCV indicate a better fitting model.

\section{Model Building}

The methods of selecting a subset of covariates in Standard Cox-PH and Shared Frailty models are essentially similar to those used in any other regression models. Thus, the model was built using Hosmer and Lemeshow (1998) recommendation.

\section{Model Diagnostics}


Residuals are a useful method for checking the fit of a statistical model. The Cox-Snell residuals, provided for checking the overall fit of the model is a residual plot used to check if a parametric distribution fits the observed data or not (Cox and Snell, 1968).

\section{Results}

\section{Descriptive Analysis}

The data for this study has been taken from 575 diabetic patients that have received treatments for more than one time in Benishangul-Gumuz hospitals (Assosa, Pawi and Wonbera hospital), Ethiopia between September 1, 2019 and September 1, 2021. The outcome was time to recovery from diabetic's disease. From the total of 1516 events, 938 (61.87\%) experienced recurrence of diabetic and the remaining $578(38.13 \%)$ were censored. The minimum and maximum recovery times of patient's diabetes were 1 and 24 month, respectively. Of all total diabetic patients in the hospitals, $90.10 \%$ have type II diabetes and the remaining $9.90 \%$ have type I diabetes. The median recovery time of diabetic patient's was 6 months.

As observed in Table 1 below, most of the diabetic patients in the hospitals, age lies between 30 and 50 years. $53.60 \%$ diabetic patients in the hospital were female and the remaining $46.40 \%$ were male patients. Looking at the education status of diabetic patients in the hospital, 51.50\% diabetic patients were uneducated. The recovery time for diabetic patients who have been married seems higher than rest of categories. More of the diabetic patients receiving treatment in the hospitals had a family history of diabetes. By observing the medication given to diabetic patients in the hospitals, the recovery time for patients receiving insulin agents only was seemed higher than other regimen groups.

By considering the specific drug given to diabetic patients in the hospitals, $63.30 \%$ diabetic patients took metformin. Diabetic patients who have other medical history before enrollment in to a chronic follow-up in the hospital as a diabetic patient was $52.50 \%$. Most of the diabetic patients receiving treatment from the hospitals had high $(130 / 80 \mathrm{mmHg})$ Blood Pressure. The weights of diabetic patients in the underweight, normal, overweight, and obesity categories were $16.50 \%, 17.20 \%, 35.50 \%$, and $30.80 \%$, respectively. 
Table 1: Descriptive Statistics Summary

\begin{tabular}{|c|c|c|c|c|}
\hline \multirow[b]{2}{*}{ Covariates } & \multirow[b]{2}{*}{ Categories } & \multicolumn{2}{|c|}{ Patients Recovery Status } & \multirow[b]{2}{*}{ Total (\%) } \\
\hline & & Censored (\%) & Event $(\%)$ & \\
\hline \multirow{3}{*}{ Age } & $<30$ & $112(7.40)$ & $182(12.00)$ & $294(19.40)$ \\
\hline & $30-50$ & $294(19.40)$ & $469(30.90)$ & $763(50.30)$ \\
\hline & $>50$ & $172(11.30)$ & $287(18.90)$ & $459(30.30)$ \\
\hline \multirow[t]{2}{*}{ Sex } & Female & $313(20.60)$ & $499(32.90)$ & $812(53.60)$ \\
\hline & Male & $265(17.50)$ & $439(29.00)$ & $704(46.40)$ \\
\hline \multirow[t]{2}{*}{ Education Status } & Uneducated & $301(19.90)$ & $479(31.60)$ & $780(51.50)$ \\
\hline & Educated & $277(18.30)$ & $459(30.30)$ & $736(48.50)$ \\
\hline \multirow{4}{*}{ Marital Status } & Single & $152(10.00)$ & $242(16.00)$ & $394(26.00)$ \\
\hline & Married & $362(23.90)$ & $590(38.90)$ & $952(62.80)$ \\
\hline & Divorced & $32(2.10)$ & $54(3.60)$ & $86(5.70)$ \\
\hline & Widowed & $32(2.10)$ & $52(3.40)$ & $84(5.50)$ \\
\hline \multirow{2}{*}{$\begin{array}{l}\text { Employment } \\
\text { Status }\end{array}$} & Unemployed & $307(20.30)$ & $484(31.90)$ & $791(52.20)$ \\
\hline & Employed & $270(17.80)$ & $454(30.00)$ & $724(47.80)$ \\
\hline \multirow{2}{*}{$\begin{array}{l}\text { Family History of } \\
\text { diabetic }\end{array}$} & No & $290(19.10)$ & $439(29.00)$ & $729(48.10)$ \\
\hline & Yes & $288(19.00)$ & $499(32.90)$ & $787(51.90)$ \\
\hline \multirow{3}{*}{ Regimen } & Oral Agents & $39(2.60)$ & $58(3.80)$ & $97(6.40)$ \\
\hline & Insulin Agents & $436(28.80)$ & $720(47.50)$ & $1156(76.30)$ \\
\hline & Oral \& Insulin Agents & $103(6.80)$ & $160(10.60)$ & $263(17.30)$ \\
\hline \multirow{7}{*}{$\begin{array}{l}\text { Specific drug } \\
\text { Used }\end{array}$} & Doanied & $66(4.40)$ & $117(7.70)$ & $183(12.10)$ \\
\hline & HCT & $31(2.00)$ & $52(3.40)$ & $83(5.50)$ \\
\hline & Metformin & $366(24.10)$ & $594(39.20)$ & $960(63.30)$ \\
\hline & Monotend & $16(1.10)$ & $26(1.70)$ & $42(2.80)$ \\
\hline & Lute & $12(0.80)$ & $14(0.90)$ & $26(1.70)$ \\
\hline & Regular & $9(0.60)$ & $16(1.10)$ & $25(1.60)$ \\
\hline & Oral & $78(5.10)$ & $119(7.80)$ & $197(13.00)$ \\
\hline \multirow{2}{*}{$\begin{array}{l}\text { Other Medical } \\
\text { History }\end{array}$} & No & $290(19.10)$ & $430(28.40)$ & $720(47.50)$ \\
\hline & Yes & $288(19.00)$ & $508(33.50)$ & $796(52.50)$ \\
\hline \multirow{3}{*}{$\begin{array}{l}\text { Systolic Blood } \\
\text { Pressure }\end{array}$} & $\operatorname{Low}(<110)$ & $58(3.80)$ & $184(12.10)$ & $242(16.00)$ \\
\hline & Normal (110-130) & $363(23.90)$ & $202(13.30)$ & $565(37.30)$ \\
\hline & $\operatorname{High}(>130)$ & $157(10.30)$ & $552(36.40)$ & $709(46.70)$ \\
\hline \multirow{3}{*}{$\begin{array}{l}\text { Diastolic Blood } \\
\text { Pressure }\end{array}$} & Low $(<60)$ & $48(3.10)$ & $135(8.90)$ & $183(12.00)$ \\
\hline & Normal (60-80) & $308(20.30)$ & $210(13.90)$ & $518(34.20)$ \\
\hline & $\operatorname{High}(>80)$ & $222(14.60)$ & $593(39.10)$ & $815(53.80)$ \\
\hline \multirow[t]{4}{*}{ Weight } & Underweight & $92(6.10)$ & $158(10.40)$ & $250(16.50)$ \\
\hline & Normal weight & $101(6.70)$ & $159(10.50)$ & $260(17.20)$ \\
\hline & Overweight & $209(13.80)$ & $330(21.70)$ & $539(35.60)$ \\
\hline & Obesity & $176(11.60)$ & $291(19.20)$ & $467(30.80)$ \\
\hline \multirow[t]{2}{*}{ Type of Diabetes } & Type I & $58(3.80)$ & $92(6.10)$ & $150(9.90)$ \\
\hline & Type II & $520(34.30)$ & $846(55.80)$ & $1366(90.10)$ \\
\hline
\end{tabular}




\section{Comparison of Recovery Time of Diabetic Patients}

As it can be observed from log-rank test Table 2 below, there is difference in the recovery time of diabetic patients for their family history, regimen, other medical history, and Blood Pressure of the patients since there corresponding p-values are smaller than the common level of significance $(5 \%)$.

Table 2: Log-rank Test for each of the Covariates

\begin{tabular}{|l|l|l|l|}
\hline Covariates & Chi-square Value & Degree of Freedom & P -value \\
\hline Age & 4.70 & 2 & 0.100 \\
\hline Sex & 0.30 & 1 & 0.600 \\
\hline Education & 0.9 & 1 & 0.600 \\
\hline Marital Status & 1.9 & 3 & 0.600 \\
\hline Employment Status & 2.70 & 1 & 0.100 \\
\hline Family History & 10.80 & 1 & 0.001 \\
\hline Regimen & 9.20 & 2 & 0.010 \\
\hline Specific Drug Used & 9.00 & 6 & 0.200 \\
\hline Other Medical History & 15.50 & 1 & $<0.0001$ \\
\hline Systolic Blood Pressure & 139.00 & 2 & $<0.0001$ \\
\hline Diastolic Blood Pressure & 78.20 & 2 & $<0.0001$ \\
\hline Weight & 2.50 & 3 & 0.500 \\
\hline
\end{tabular}

\section{Recurrent Model}

\section{Standard Cox Proportional Hazard Model}

To determine the effect of each covariate on the recovery time of diabetic patients, Cox proportional hazard model was fitted before proceeding to more complicated models. Result of the univariable standard Cox-PH model is shown in the Appendix (Table 8). As this result shows ,family history, other medical history, and Blood Pressure of patients are significantly affecting the recovery time of diabetic patients.

The fitted Standard Cox-PH model, as shown in Table 3 below, shows that the recovery time of the diabetic patient's significantly affected by family history, other medical history, and Systolic Blood Pressure of patients. The Standard Cox-PH model considers different lines of data contributed by the same subjects as independent contributions from different subjects. 
Table 3: Parameter Estimates of Standard Cox-PH Model

\begin{tabular}{|c|c|c|c|c|c|c|}
\hline Covariates & Categories & Coef & $\operatorname{Exp}($ coef $)$ & SE [Coef(HIH)] & $95 \% \mathrm{CI}$ & P-value \\
\hline \multirow{2}{*}{$\begin{array}{l}\text { Family Histo- } \\
\text { ry of diabetic }\end{array}$} & No & & & & & \\
\hline & Yes & 0.1329 & 1.1421 & 0.0663 & {$[1.00,1.30]$} & 0.0393 \\
\hline \multirow{3}{*}{ Regimen } & Oral Agents & & & & & \\
\hline & Insulin Agents & 0.1836 & 1.2016 & 0.1376 & {$[0.92,1.57]$} & 0.1902 \\
\hline & Both & 0.1029 & 1.1084 & 0.1537 & {$[0.82,1.50]$} & 0.5030 \\
\hline \multirow{2}{*}{$\begin{array}{l}\text { Other Medical } \\
\text { History }\end{array}$} & No & & & & & \\
\hline & Yes & 0.1315 & 1.1406 & 0.0663 & {$[1.00,1.30]$} & 0.0472 \\
\hline \multirow{3}{*}{$\begin{array}{l}\text { Systolic } \\
\text { Blood } \\
\text { Pressure }\end{array}$} & Low & & & & & \\
\hline & Normal & -0.4237 & 0.6546 & 0.1170 & {$[0.52,0.82]$} & 0.0003 \\
\hline & High & -0.0903 & 0.913656 & 0.0986 & {$[0.75,1.11]$} & 0.3596 \\
\hline \multirow{3}{*}{$\begin{array}{l}\text { Diastolic } \\
\text { Blood } \\
\text { Pressure }\end{array}$} & Low & & & & & \\
\hline & Normal & -0.0925 & 0.9116 & 0.1254 & {$[0.71,1.17]$} & 0.4605 \\
\hline & High & 0.1259 & 1.1341 & 0.1102 & {$[0.91,1.41]$} & 0.2537 \\
\hline \multicolumn{7}{|c|}{$\begin{array}{l}\text { penalized marginal log-likelihood }=-2517.41 ; \text { Convergence criteria: } \text { parameters }=2.33 e-06 ; \text { likelihood } \\
=4.05 \text { e-05 gradient }=1.77 e-07 ; L C V=\text { the approximate likelihood cross-validation criterion in the } \\
\text { semi parametrical case }=1.67106\end{array}$} \\
\hline \multicolumn{7}{|c|}{$\begin{array}{l}\text { Coef: estimated coefficient for each covariates; Exp (coef): exponentiation value of coefficient, se coef (H) } \\
\text { and hr is hazard ratio. }\end{array}$} \\
\hline
\end{tabular}

\section{Checking the Assumption of Cox-PH}

The assumption of Cox-PH model by considering a variable included in the model was checked using the Schoenfeld residuals as described in Table 4 below. Observing the results from this Table the covariates are not statistically significant, implying that the covariates are time independent. The overall proportionality test is also not statistically significant, implying that the proportionality assumption was not violated.

Table 4: Test of Assumption for Cox-PH Model

\begin{tabular}{|l|l|l|l|l|}
\hline Covariates & rho & Chi-square Value & Degree of Freedom & P -value \\
\hline Family History & 0.033 & 0.529 & 1 & 0.470 \\
\hline Regimen & -0.002 & 1.625 & 2 & 0.440 \\
\hline Other Medical History & 0.042 & 1.046 & 1 & 0.310 \\
\hline Systolic Blood Pressure & 0.147 & 1.649 & 2 & 0.440 \\
\hline Diastolic Blood Pressure & 0.131 & 1.076 & 2 & 0.580 \\
\hline GLOBAL & NA & 6.530 & 8 & 0.590 \\
\hline
\end{tabular}

\section{Shared Gamma Frailty Model}


In the Shared Gamma Frailty model, the clustered structure of the data is taken into account with interest of considering the heterogeneity between subjects. As usual, the first univariable analysis was conducted and significant variables at $25 \%$ level of significance were taken in the multiple Shared Gamma Frailty model.

The result of the univariable Shared Gamma Frailty model is shown in the Appendix (Table 8). As it can be observed from the result, family history, regimen, other medical history, and Blood Pressure of patients are significantly affecting the recovery time of diabetic patients. The fitted Shared Gamma Frailty model, as shown in Table 5 below, showed that the recovery time of the diabetic patient's significantly affected by family history, other medical history and Systolic Blood Pressure of patients.

Table 5: Parameter Estimates of Shared Gamma Frailty Model

\begin{tabular}{|c|c|c|c|c|c|c|}
\hline Covariates & Categories & Coef & $\operatorname{Exp}($ coef) & SE [Coef(HIH)] & $95 \% \mathrm{CI}$ & P-value \\
\hline \multirow{2}{*}{$\begin{array}{l}\text { Family Histo- } \\
\text { ry of diabetic }\end{array}$} & No & & & & & \\
\hline & Yes & 0.1223 & 1.1301 & 0.0662 & {$[1.00,1.29]$} & 0.0065 \\
\hline \multirow{3}{*}{ Regimen } & Oral Agents & & & & & \\
\hline & Insulin Agents & 0.2004 & 1.2219 & 0.1378 & {$[0.93,1.60]$} & 0.1550 \\
\hline & Both & 0.1407 & 1.1510 & 0.1540 & {$[0.85,1.56]$} & 0.3658 \\
\hline \multirow{2}{*}{$\begin{array}{l}\text { Other Medi- } \\
\text { cal History }\end{array}$} & No & & & & & \\
\hline & Yes & 0.1358 & 1.1454 & 0.0663 & {$[1.01,1.30]$} & 0.0040 \\
\hline \multirow{3}{*}{$\begin{array}{l}\text { Systolic } \\
\text { Blood } \\
\text { Pressure }\end{array}$} & Low & & & & & \\
\hline & Normal & -0.4540 & 0.6351 & 0.1165 & {$[0.51,0.80]$} & $<0.0001$ \\
\hline & High & -0.0846 & 0.9189 & 0.0979 & {$[0.76,1.11]$} & 0.0387 \\
\hline \multirow{3}{*}{$\begin{array}{l}\text { Diastolic } \\
\text { Blood } \\
\text { Pressure }\end{array}$} & Low & & & & & \\
\hline & Normal & -0.1231 & 0.8841 & 0.1247 & {$[0.69,1.13]$} & 0.2577 \\
\hline & High & 0.1205 & 1.1281 & 0.1095 & {$[0.91,1.40]$} & 0.3020 \\
\hline \multicolumn{7}{|c|}{ Frailty parameter, $2.66283 e-17 ; S E(H): 4.27331 e-10 ; p=0.5$} \\
\hline \multicolumn{7}{|c|}{$\begin{array}{l}\text { penalized marginal log-likelihood }=-2508.6 ; \text { Convergence criteria: } \text { parameters }=2.29 e-08 ; \text { likelihood }= \\
3.07 e-07 ; \text { gradient }=1.12 e-12 ; L C V=\text { the approximate likelihood cross-validation criterion } \text { in the semi } \\
\text { parametrical case }=1.66661\end{array}$} \\
\hline \multicolumn{7}{|c|}{$\begin{array}{l}\text { Coef: estimated coefficient for each covariates; Exp (coef): exponentiation value of coefficient, se coef (H) } \\
\text { and hr is hazard ratio. }\end{array}$} \\
\hline
\end{tabular}

\section{Shared Log-Normal Frailty Model}

As in Shared Gamma Frailty model, for Shared Log-Normal Frailty model, the clustered structure of the data is taken into account with the interest in considering the heterogeneity between subjects. The result of the univariable Shared Gamma Frailty model is shown in the Appendix (Table 8). As it can be observed from the result, family history, regimen, other 
medical history, and Blood Pressure of patients are significantly affecting the recovery time of diabetic patients. The multivariable Shared Log-Normal Frailty model is shown as in Table 6 below. Thus, the result shows that the recovery time of diabetic patient's significantly affected by family history, other medical history, and Systolic Blood Pressure of patients.

Table 6: Parameter Estimates of Shared Log-Normal Frailty Model

\begin{tabular}{|c|c|c|c|c|c|c|}
\hline Covariates & Categories & Coef & $\operatorname{Exp}($ coef $)$ & $\mathrm{SE}[\mathrm{Coef}(\mathrm{HIH})]$ & $95 \% \mathrm{CI}$ & P-value \\
\hline \multirow{2}{*}{$\begin{array}{l}\text { Family Histo- } \\
\text { ry of diabetic }\end{array}$} & No & & & & & \\
\hline & Yes & 0.1527 & 1.1650 & 0.0711 & {$[1.01,1.34]$} & 0.0318 \\
\hline \multirow{3}{*}{ Regimen } & Oral Agents & & & & & \\
\hline & Insulin Agents & 0.2177 & 1.2432 & 0.1467 & {$[0.93,1.66]$} & 0.1379 \\
\hline & Both & 0.1547 & 1.1672 & 0.1640 & {$[0.85,1.61]$} & 0.3460 \\
\hline \multirow{2}{*}{$\begin{array}{l}\text { Other Medi- } \\
\text { cal History }\end{array}$} & No & & & & & \\
\hline & Yes & 0.1616 & 1.1754 & 0.0711 & {$[1.02,1.35]$} & 0.0230 \\
\hline \multirow{3}{*}{$\begin{array}{l}\text { Systolic Blood } \\
\text { Pressure }\end{array}$} & Low & & & & & \\
\hline & Normal & -0.4601 & 0.6312 & 0.1220 & {$[0.50,0.80]$} & 0.0003 \\
\hline & High & -0.0907 & 0.9133 & 0.1036 & {$[0.75,1.12]$} & 0.3814 \\
\hline \multirow{3}{*}{$\begin{array}{l}\text { Diastolic } \\
\text { Blood } \\
\text { Pressure }\end{array}$} & Low & & & & & \\
\hline & Normal & -0.1101 & 0.8957 & 0.1308 & {$[0.69,1.16]$} & 0.3997 \\
\hline & High & 0.1346 & 1.1441 & 0.1156 & {$[0.91,1.43]$} & 0.2442 \\
\hline \multicolumn{7}{|c|}{ Frailty parameter, Sigma Square: 0.0757467; SE (H): 0.00742001; $p=<1 e-16$} \\
\hline \multicolumn{7}{|c|}{$\begin{array}{l}\text { penalized marginal log-likelihood }=-2506.04 ; \text { Convergence criteria: } \text { parameters }=5.54 e-11 ; \text { likelihood }= \\
1.35 \text {-07; gradient }=6.92 e-16 ; L C V=\text { the approximate likelihood cross-validation criterion in the semi } \\
\text { parametrical case }=1.66625\end{array}$} \\
\hline
\end{tabular}

\section{Testing Frailty Effect of Shared Frailty Model}

Test hypothesis for the variance term of both Shared Gamma and Log-Normal Frailty terms is given by:

$$
H_{0}: \theta=0 \text { or } H_{0}: \delta^{2}=0 \quad \text { VS } \quad H_{1}: \theta>0 \text { or } H_{1}: \delta^{2}>0
$$

The variance of the Frailty term Theta and Sigma Square are significantly different from zero, meaning that there is heterogeneity between subjects. The modified Wald Test Values for Shared Gamma Frailty and Shared Log-Normal Frailty model are $W_{m}(\theta)=7.564 \exp (-12)$ and $W_{m}\left(\delta^{2}\right)=10.216$, respectivly. Looking at Table 5 and Table 6 above, the p-value for the Shared Log-normal Frailty model, but not for Shared Gamma Frailty model, is less than 5\%. This means 
that there is a significant Frailty effect; that is, within-subject the correlation cannot be ignored for Shared Log-normal Frailty model but not for Shared Gamma Frailty model.

\section{Comparison of Standard Cox-PH and Shared Frailty Model}

In this study, the model based and empirically corrected standard errors $\left(H^{-1}\right.$ and $\left.H^{-1} I H^{-1}\right)$ were almost identical for each model used. Comparing the estimated standard errors presented in Table 4, Table 5, and Table 6 above, slight differences were observed in the standard error for Standard Cox-PH model and Shared Frailty model. As expected, the standard errors of the Shared Gamma Frailty and Shared Log-Normal Frailty model were slightly larger than standard errors of the Standard Cox-PH model.

Efficiency of the fitted models was compared using penalized marginal log-likelihood and LCV (likelihood cross-validation) criterion. The likelihood cross-validation criterion assesses the goodness of fit of a statistical model (Gray, 1992 and approximately equivalent to Akaike Information criterion (AIC) for the parametric models. Table 7 below shows the LCV result of standard Cox- PH, Shared Gamma Frailty and Shared Log-Normal Frailty models. Accordingly, the Shared log-Normal Frailty model was chosen as the best fit for the data in this study.

Table 7: Comparison of Standard Cox-PH and Shared Frailty Model

\begin{tabular}{|l|l|l|l|l|}
\hline Model & $\begin{array}{l}\text { Frailty } \\
\text { Parameter }\end{array}$ & $\begin{array}{l}\text { Standard } \\
\text { Error }\end{array}$ & $\begin{array}{l}\text { Penalized Marginal } \\
\text { Log-Likelihood }\end{array}$ & LCV \\
\hline Standard Cox-PH & - & - & -2517.41 & 1.67106 \\
\hline Shared Gamma Frailty & $2.66283 \mathrm{e}-17$ & $4.27331 \mathrm{e}-11$ & -2508.60 & 1.66661 \\
\hline Shared Log-Normal Frailty & 0.0757467 & 0.00742001 & -2506.04 & $\mathbf{1 . 6 6 6 2 5}$ \\
\hline
\end{tabular}

\section{Interpretation of Final Fitted Model}

The Shared Log-normal Frailty model was chosen as the best fit for the recurrent events data of diabetes based on the LCV. Therefore, the final fitted model was Shared Log-Normal Frailty model as shown in Table 6 above. Family history, other medical history, and Systolic Blood Pressure were the only significant covariates selected from the saturated multiple Shared Lognormal Frailty model. 
The estimated hazard rate for Patients with family history of diabetes is 1.1650 with [95\% CI: 1.01, 1.34]. This result shows that the expected hazard rate of diabetic patients to have a normal fasting Blood Sugar Level who have a family history of diabetes is 1.650 times higher than patients who have no family history of diabetes by keeping the effect of other factors constant and accounting for frailty. The 95\% confidence interval for hazard rate of patients family history of diabetes did not include one and $p$-value is small ( $p$-value $=0.0318)$, which implies that patients family history of diabetes had a significant effect on the recovery time of diabetic patients.

Looking at other medical history, keeping the effect of other factors constant and accounting for frailty, the expected hazard rate of diabetic patients to have a normal fasting Blood Sugar Level who have other medical history of diabetes is 1.1754 times higher than patients who have no other medical history of diabetes, since the estimated hazard rate for patients with other medical history of the diabetes is 1.1754 with [95\% CI: 1.02, 1.35]. The 95\% confidence interval for the hazard rate of patients with other medical history of diabetes did not include one and p-value is small ( $p$-value $=0.0230)$, which implies that patients with other medical history of diabetes have a significant effect on the recovery time of diabetic patients.

Finally, observing for Systolic Blood Pressure, keeping the effect of other factors constant, and accounting for frailty, the expected hazard rate of diabetic patients to have normal fasting Blood Sugar Level who have normal systolic blood pressure is 0.6312 times less than patients who have low systolic blood pressure, since the estimated hazard rate for patients normal systolic blood pressure of the diabetes is with [95\% CI: 0.50, 0.80]. The 95\% confidence interval for the hazard rate of patients with normal systolic blood pressure of the diabetes did not include one and pvalue is small ( $\mathrm{p}$-value $=0.0003$, which implies that patients systolic blood pressure of diabetes had a significant effect on the recovery time of diabetic patients.

\section{Model Diagnostic}

By observing Cox-Snell residuals plot Figure 1 below, the Shared Log-normal Frailty model fits the recurrent data of diabetic patients; since the plot of Cox-Snell residuals against the cumulative hazard function of residuals is approximately a straight line with slope one. 


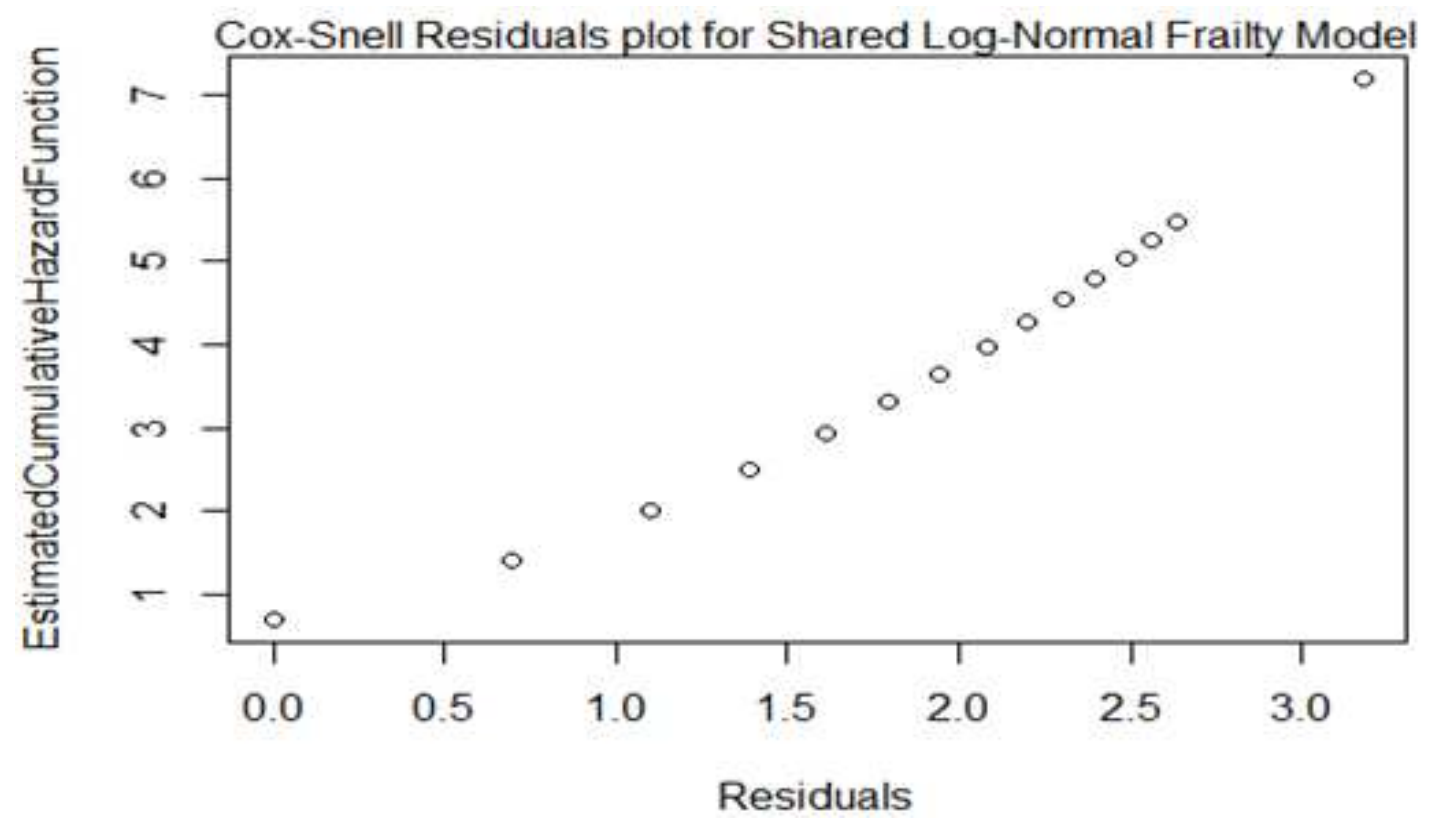

Figure 1: Cox-Snell Residuals Plot

\section{Discussion}

The main aim of this study was to identify factors affecting the recurrence of patients diabetes data set, which was obtained from Benishangul-Gumuz hospitals (Assosa,Pawi and Wonbera hospital). The Cox-PH model was applied for this data since the assumption of Cox-PH model was not violated. However, the common Cox model only considers the time until the first occurring event, meaning that all events after the first are neglected. The most frequently applied analysis method for recurrent time-to-event data is the model by Andersen and Gill (1983), which is based on the common Cox proportional hazards model (Cox,1972). The Andersen-Gill model assumes independence between all observed event times irrespective whether these event times correspond to the same patient or to different patients. In addition, Frailty models will be used to account for the dependence among the recurrent event times based on Andersen-Gill (AG) survival model.

From 575 diabetic patients, 518(90.10\%) were Type-II diabetic and the remaining 57 (9.90\%) were Type-I diabetic. Of all 1516 events, 938 (61.87\%) experienced recurrence of diabetic and the remaining $578(38.13 \%)$ were censored. The minimum and maximum recovery times of patient's diabetes were 1 and 24, month respectively. The median recovering time of the diabetic patients was 6 month. 
Under univariable analysis, the Shared Log-normal Frailty model shows that family history, regimen, other medical history, and Blood Pressure were significantly associated with recurrence of diabetic patients at $5 \%$ level of significance.

By considering multivariable analysis result from Standard Cox-PH, Shared Gamma Frailty and Shared Log-normal Frailty model the recovery time of diabetic patient's significantly affected by family history, other medical history and Systolic Blood Pressure of patients. LCV values of for the standard Cox-PH, Shared Gamma Frailty and for Shared Log-normal Frailty models were 1.67106, 1.66661 and 1.66625 respectively. Thus, the Shared Log-normal Frailty model was chosen to be best fit for this data set, since LCV value for the Shared Log-normal Frailty model was minimum as compared to the Standard Cox-PH and Shared Gamma Frailty models.

The heterogeneity parameters of $\theta$ and $\sigma^{2}$ are estimated to be: 2.66283e-17 [with SE (H) $=4.27331 e-10 ; p=0.5$ ] and: 0.0757467 [with SE (H): 0.00742001; $p=<1 e-16$ ] for the Shared Gamma Frailty and Shared Log-normal Frailty models respectively. This result suggests that there is a significant Frailty effect for Shared Log-normal Frailty model but not for Shared Gamma Frailty model. This means that, in the Shared Log-normal Frailty model the correlation within the cluster patients cannot be ignored.

The study done by InterAct Consortium: Scott et al. (2013) showed that the recovery time of diabetic patients was significantly affected by family history of diabetes and the expected recovery time of diabetic patients to have a normal fasting Blood Sugar Level who have a family history of diabetes was less than patients who have no family history of diabetes. This study was consistent with the current study.

The recovery time of diabetic patients was significantly affected by other medical history of diabetes; the expected recovery time of diabetic patients to have normal fasting Blood Sugar Level who have other medical history of diabetes was less than patients who have no other medical history of diabetes. This study was justified by the study done by Leon and Maddox (2015).

On the other hand, the study done by (Emdin et al., 2015) showed that systolic blood pressure was significantly affected the recovery time of diabetic patients. The recovery time of diabetic patients to have normal fasting Blood Sugar Level who have normal systolic blood pressure was 
less than patients who have low systolic blood pressure. This study was agreed with the current study.

\section{Conclusion}

This study used the recurrent data sets that have been taken from diabetic patients, for those patients who were receiving treatment for more than one time from September 1, 2019 to September 1, 2021, in Benishangul-Gumuz hospitals (Assosa, Pawi and Wombera hospital); with the aim to identify risk factors for recurrence of diabetic patients recovery time. From the total of 575 diabetic patients, $61.87 \%$ experienced recurrence of diabetic and the remaining 38.13\% were censored. Fifty percent of the diabetic patient's recovery time was 6 months or above it.

To identify risk factors for recurrence of diabetic patient's recovery time, recurrent models: standard Cox-PH, Shared Gamma Frailty and Shared Log-normal Frailty were fitted. The Shared Log-normal Frailty model was chosen to be the best fit for this data set, based on LCV values. Family history, other medical history, and Systolic Blood Pressure of patients were significantly affected the recovery time of diabetic patient's.

\section{Abbreviations}

AMECA: Alex's Medical and Educational Clinic in Africa; CNCDs: Non-Communicable Chronic Diseases; Cox-PH: Cox Proportional Hazard; FGD: Focus Group Discussion; IDF Internationals Diabetes Federation; LCV: Likelihood Cross-Validation; NCD-RisC: NonCommunicable Diseases Risk Factor Collaboration; T1D: Type 1 Diabetes; T2D: Type 2 Diabetes; WHO: World Health Organization

\section{Declarations}

\section{Acknowledgment}

We acknowledge all study participants from starting to end.

\section{Funding}

Not applicable

\section{Availability of Data}


The data will be given upon request on behalf of the corresponding author

\section{Ethical Consideration}

The Research Ethics Review Board of Assosa University would provide an ethical clearance for the study. The data has been collected after written permission was given to BenishangulGumuz hospitals and Assosa University Research Directors write an official cooperation letter to the hospitals for the permission. The data obtained from the hospitals were kept confidentially.

\section{Consent for Publication}

Not applicable

\section{Conflict of interest}

The authors do not have any conflict of interest.

\section{Authors' Contributions}

Both researchers conduct the research and write the manuscript.

\section{Statistical Software Used}

SPSS version 20 for data coding and entry; R version 4.1.1 for data analysis

\section{References}

Aalen, O., 2008 Survival and Event History Analysis. Springer-Verlag, New York.

Abiyot Negash, Dr. Yehenew Getachew, Belay Birlie (2014): 'Modeling Time-to- Frist Recovery of Adult Diabetic Patients': A Case Study of Jimma University Specialized Hospital, Ethiopia.

Ambachew Y, Kahsay S, Tesfay R, Tesfahun L, Amare H, G/her G and Mehari A. 'Prevalence of Diabetes Mellitus among Patients Visiting Medical Outpatient Department of Ayder Referral Hospital, Mekelle, Ethiopia: A Three Years Pooled Data'. International Journal of Pharma Sciences and Research (IJPSR), 2015; 6(2):435-9.

AMECA. Alex's Medical and educational clinic in Africa. Ethiopia: Black Lion Specialized Hospital, AMECA; 2015. 
Andersen, PK., Gill, RD., 1982 Cox's regression model for counting processes: A large sample study. Ann Stat pp.1100-20.

Assaye Belay, Bizuwork Derebew, Solomon Abebaw (2021). 'Survival Analysis on Time-ToRecovery of Diabetic Patients at Minlik Referral Hospital, Ethiopia: Retrospective Cohort Study'. DOI: https://doi.org/10.21203/rs.3.rs-1015864/v1

Cox, D. R. and Snell, E. J., 1968 A general definitions of residuals with discussion. Atlanta

Cox DR. Regression models and life-tables. J R Stat Soc Series B (Methodological). 1972;34(2):187\{220.

Dereje, N. et al. 'Prevalence and Associated Factors of Diabetes Mellitus in Hosanna Town, Southern Ethiopia'. Annals of Global Health. 2020; 86(1): 18, 1-9. DOI: https://doi.org/10.5334/aogh.2663

Duchateau, L. and Janssen P., 2008: The Frailty Model. Springer-Verlag, New York. Failure Time Models https://core.ac.uk/download/pdf/55298480.pdf

Emdin CA, Anderson SG, Woodward M, Rahimi K. 'Usual Blood Pressure and Risk of NewOnset Diabetes: Evidence from 4.1 Million Adults and a Meta-Analysis of Prospective Studies'. J Am Coll Cardiol. 2015;66(14):1552-1562. doi:10.1016/j.jacc.2015.07.059

Gizaw M, Harries AD, Ade S, Tayler-Smith K, Ali E, Firdu N, and Yifter H. 'Diabetes mellitus in Addis Ababa, Ethiopia: admissions, complications and outcomes in a large referral hospital'. Public Health Action, 2015; 5(1):74-8.

GLOBAL BURDEN OF DISEASE RISK FACTORS COLLABORATORS. 'Global, regional, and national comparative risk assessment of 79 behavioural, environmental and occupational, and metabolic risks or clusters of risks in 188 countries, 1990-2013: a systematic analysis for the Global Burden of Disease Study 2013'. Lancet. 2015;386(10010):2287-323.

Grambsch, P.M. and Therneau, T.M., 1994 'Proportional Hazards Tests and Diagnostics Based on Weighted Residuals'. Biometrika, 81, 515-526. https://doi.org/10.1093/biomet/81.3.515

Gray, RJ., 1992) Flexible methods for analyzing survival data using splines, with application to breast cancer prognosis; JASA, 87 942-951 
Hosmer, D., and Lemeshow, S., 1998 Applied Survival Analysis Regression Modeling of Time to Event Data. John Wiley and Sons, New York

Hossam, A., 2014 'Overview on Diabetes'; https://www.researchgate.net/publication/270283336

InterAct Consortium, Scott RA et al. The link between family history and risk of type 2 diabetes is not explained by anthropometric, lifestyle or genetic risk factors: the EPICInterAct study. Diabetologia. 2013;56(1):60-69. doi:10.1007/s00125-012-2715-X

INTERNATIONAL DIABETES FEDERATION. IDF Diabetes Atlas, 10th edn. Brussels, Belgium: 2021. Available at: https://www.diabetesatlas.org

Kaplan, EL. and Meier P., 1958 Non-parametric estimation from incom plete observations. J am Stat Assoc 1958(53):45781

Kleinbaum, DG. and Klein, M., 2011 Survival analysis a self-learning text, 3rd edn. Springer, New York

Leon, BM. And Maddox, TM. 'Diabetes and cardiovascular disease: Epidemiology, biological mechanisms, treatment recommendations and future research'. World $J$ Diabetes. 2015;6(13):1246-1258. doi:10.4239/wjd.v6.i13.1246

Nshisso LD, Reesea A, Gelaye B, Lemma S, Berhane Y, and Williams MA. 'Prevalence of Hypertension and Diabetes among Ethiopian Adults'. Diabetes Metab Syndr, 2012;6(1):36- 41.

Pickels, A., Crouchley, R., Simono_, E.L., Meyer, J., Rutter, M., Hewitt, J. and Silbery, J. (1994): 'Survival models for developmental genetic data: Age at onset of puberty and antisocial behavior in twins'. Genetic Epidemiology, 11: 155-170.

Thomas RL, Distiller L, Luzio SD, Melville VJ, Roy Chowdhury S, Kramer B, Owens DR. (2015) 'Incidence and Progression of Diabetic Retinopathy with in a Private Diabetes Mellitus Clinic in South Africa'. J Endocrinol. 2015;20(3):127-33.

WORLD HEALTH ORGANIZATION (2021) Definition, diagnosis and classification of diabetes mellitus and its complications. 
Yashin, A.I., Vaupel, J.W., and Jachine, I.A. (1995) 'Correlated individual Frailty: An advantageous approach to survival analysis of bivariate data'. Mathematical population studies, 5:145-149.

Zekewos A, Loha E, Egeno T, Wubshet K, Merga Z. Prevalence of Diabetes Mellitus and Associated Factors in Bona District, Sidama Zone: A Community Based Study. Ethiop J Health Sci.2018; 28 (4):451. doi:http://dx.doi.org/ 10.4314/ejhs. v28i4.11 


\section{Appendix}

Table 8: Shows Univariate Analysis of Recurrent Model

\begin{tabular}{|c|c|c|c|c|c|c|c|}
\hline \multirow{3}{*}{ Covariates } & \multirow{3}{*}{ Categories } & \multicolumn{6}{|c|}{ Model Used } \\
\hline & & \multicolumn{2}{|c|}{ Standard Cox-PH } & \multicolumn{2}{|c|}{ Shared Gamma Frailty } & \multicolumn{2}{|c|}{ Shared Log-normal Frailty } \\
\hline & & $\hat{\beta}[\mathrm{SE}(\hat{\beta})]$ & P-value & $\hat{\beta}[\mathrm{SE}(\hat{\beta})]$ & P-value & $\hat{\beta}[\operatorname{SE}(\hat{\beta})]$ & P-value \\
\hline \multirow{3}{*}{ Age } & $<30$ & & & & & & \\
\hline & $30-50$ & $\begin{array}{l}-0.135 \\
{[0.087]}\end{array}$ & 0.123 & $-0.126[0.087]$ & 0.148 & $-0.137[0.094]$ & 0.144 \\
\hline & $>50$ & $\begin{array}{l}-0.019[ \\
0.095]\end{array}$ & 0.844 & $-0.021[0.095]$ & 0.828 & $-0.018[0.102]$ & 0.859 \\
\hline \multirow[t]{2}{*}{ Sex } & Female & & & & & & \\
\hline & Male & $0.048[0.065]$ & 0.464 & $0.033[0.066]$ & 0.611 & $0.0480[0.0703]$ & 0.4948 \\
\hline \multirow{2}{*}{$\begin{array}{l}\text { Education } \\
\text { Status } \\
\end{array}$} & Uneducated & & & & & & \\
\hline & Educated & $0.043[0.065]$ & 0.509 & $0.031[0.065]$ & 0.611 & $0.040[0.0702]$ & 0.5698 \\
\hline \multirow{2}{*}{$\begin{array}{l}\text { Family Histo- } \\
\text { ry of diabetic }\end{array}$} & No & & & & & & \\
\hline & Yes & $0.172[0.066]$ & 0.009 & $0.144[0.066]$ & 0.028 & $0.176[0.070]$ & 0.012 \\
\hline \multirow{3}{*}{ Regimen } & Oral Agents & & & & & & \\
\hline & Insulin Agents & $0.301[0.136]$ & 0.028 & $0.285[0.137]$ & 0.037 & $0.312[0.146]$ & 0.032 \\
\hline & Both & $0.170[0.153]$ & 0.268 & $0.164[0.153]$ & 0.286 & $0.182[0.1637]$ & 0.266 \\
\hline \multirow{7}{*}{$\begin{array}{l}\text { Specific drug } \\
\text { Used }\end{array}$} & Doanied & & & & & & \\
\hline & $\mathrm{HCT}$ & $\begin{array}{l}-0.120 \\
{[0.167]}\end{array}$ & 0.231 & $-0.192[0.167]$ & 0.251 & $-0.207[0.179]$ & 0.249 \\
\hline & Metformin & $-0.060[0.101]$ & 0.551 & $-0.042[0.101]$ & 0.681 & $-0.064[0.109]$ & 0.560 \\
\hline & Monotend & $0.194[0.217]$ & 0.371 & $0.165[0.217]$ & 0.448 & $0.208[0.236]$ & 0.377 \\
\hline & Lute & $-0.426[0.283]$ & 0.133 & $-0.378[0.283]$ & 0.182 & $-0.438[0.299]$ & 0.143 \\
\hline & Regular & $0.155[0.267]$ & 0.560 & $0.138[0.267]$ & 0.607 & $0.149[0.287]$ & 0.603 \\
\hline & Oral & $-0.116[0.130]$ & 0.374 & $-0.082[0.130]$ & 0.530 & $-0.123[0.140]$ & 0.378 \\
\hline \multirow{2}{*}{$\begin{array}{l}\text { Other Medi- } \\
\text { cal History }\end{array}$} & No & & & & & & \\
\hline & Yes & $0.160[0.066]$ & 0.015 & $0.142[0.066]$ & 0.031 & $0.164[0.071]$ & 0.021 \\
\hline \multirow{3}{*}{$\begin{array}{l}\text { Systolic } \\
\text { Blood } \\
\text { Pressure } \\
\end{array}$} & Low & & & & & & \\
\hline & Normal & $-0.470[0.104]$ & $<0.0001$ & $-0.489[0.104]$ & $<0.0001$ & $-0.496[0.108]$ & $<0.0001$ \\
\hline & High & $-0.006[0.085]$ & 0.095 & $-0.018[0.085]$ & 0.083 & $-0.020[0.090]$ & 0.081 \\
\hline \multirow{3}{*}{$\begin{array}{l}\text { Diastolic } \\
\text { Blood } \\
\text { Pressure }\end{array}$} & Low & & & & & & \\
\hline & Normal & $-0.303[0.111]$ & 0.007 & $0.327[0.111]$ & 0.003 & $-0.322[0.116]$ & 0.005 \\
\hline & High & $0.070[0.096]$ & 0.467 & $0.045[0.096]$ & 0.638 & $0.054[0.100]$ & 0.589 \\
\hline \multirow[t]{4}{*}{ Weight } & Underweight & & & & & & \\
\hline & Normal & $-0.060[0.112]$ & 0.596 & $-0.051[0.112]$ & 0.652 & $-0.058[0.121]$ & 0.628 \\
\hline & Overweight & $-0.071[0.097]$ & 0.462 & $-0.067[0.097]$ & 0.489 & $-0.072[0.104]$ & 0.489 \\
\hline & Obesity & $-0.010[0.099]$ & 0.920 & $-0.014[0.099]$ & 0.887 & $-0.012[0.107]$ & 0.912 \\
\hline
\end{tabular}




\section{Table 9: Show Median Recovery Time for Diabetic Data}

\begin{tabular}{|c|c|c|c|c|c|c|c|c|c|}
\hline \multicolumn{10}{|c|}{ Here is the estimated probability of recovery time for recurrence of diabetic patients } \\
\hline Time & n.risk & neven & nt Recavery & y std_err lov & pwer $95 \% 6 \mathrm{Cl}$ & upper $95 \%$ & $\mathrm{Cl}$ & & \\
\hline 1 & 1516 & 1 & 0.9993 & 0.000659 & 0.99805 & 1.0000 & & & \\
\hline 2 & 1514 & 73 & 0.9512 & 0.005538 & 0.94036 & 0.9621 & & & \\
\hline 3 & 1416 & 132 & 0.8625 & 0.008901 & 0.84522 & 0.8801 & & & \\
\hline 4 & 1207 & 182 & 0.7324 & 0.011664 & 0.70993 & 0.7557 & & & \\
\hline 5 & 920 & 190 & 0.5812 & 0.013462 & 0.55538 & 0.6082 & & & \\
\hline 6 & 635 & 163 & 0.4320 & 0.014199 & 0.40504 & 0.4607 & n & events & medisn \\
\hline 7 & 376 & $B 2$ & 0.3378 & 0.014419 & 0.31067 & 0.3679 & 1516 & 938 & 6 \\
\hline 8 & 219 & 51 & 0.2591 & 0.014677 & 0.23189 & 0.2895 & & & \\
\hline 9 & 114 & 49 & 0.1477 & 0.014641 & 0.12166 & 0.1794 & & & \\
\hline 10 & 39 & 6 & 0.1250 & 0.015045 & 0.09875 & 0.1583 & & & \\
\hline 11 & 16 & 3 & 0.1016 & 0.017269 & 0.07279 & 0.1417 & & & \\
\hline 12 & 8 & 2 & 0.0762 & 0.020238 & 0.04526 & 0.1282 & & & \\
\hline 13 & 6 & 3 & 0.0381 & 0.018553 & 0.01466 & 0.0989 & & & \\
\hline 14 & 3 & 1 & 0.0254 & 0.016138 & 0.00731 & 0.0882 & & & \\
\hline
\end{tabular}

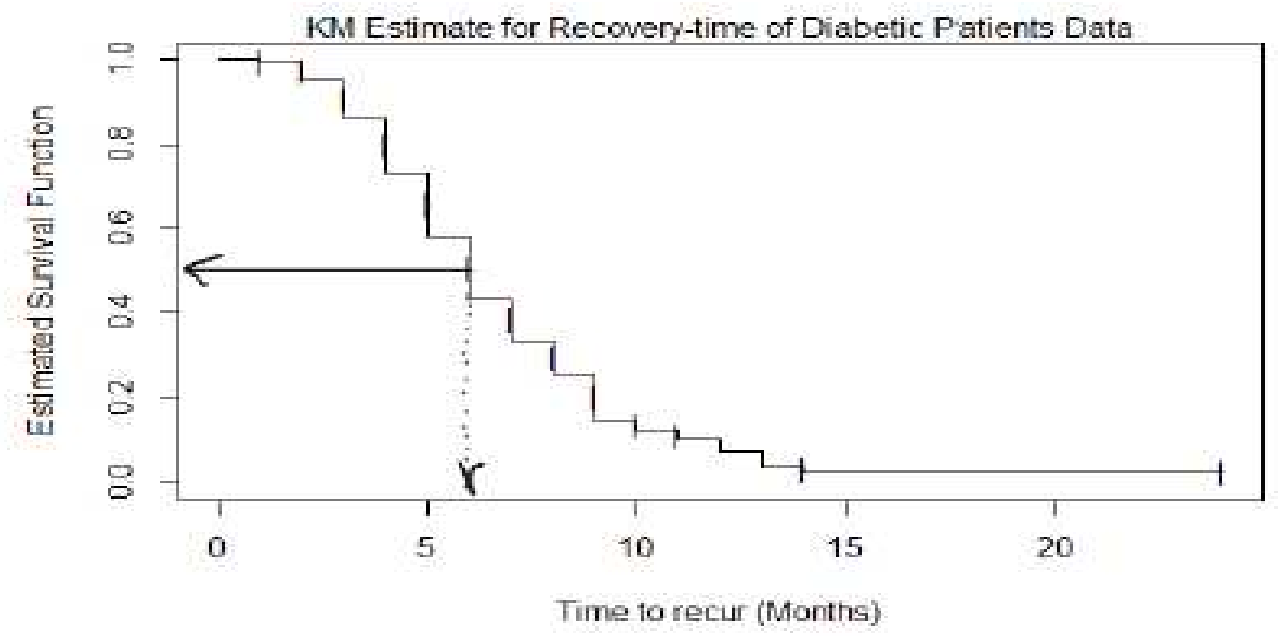

Figure 2: Kaplan-Meier Estimate plot for Recovery Time of Diabetic Patients Data 

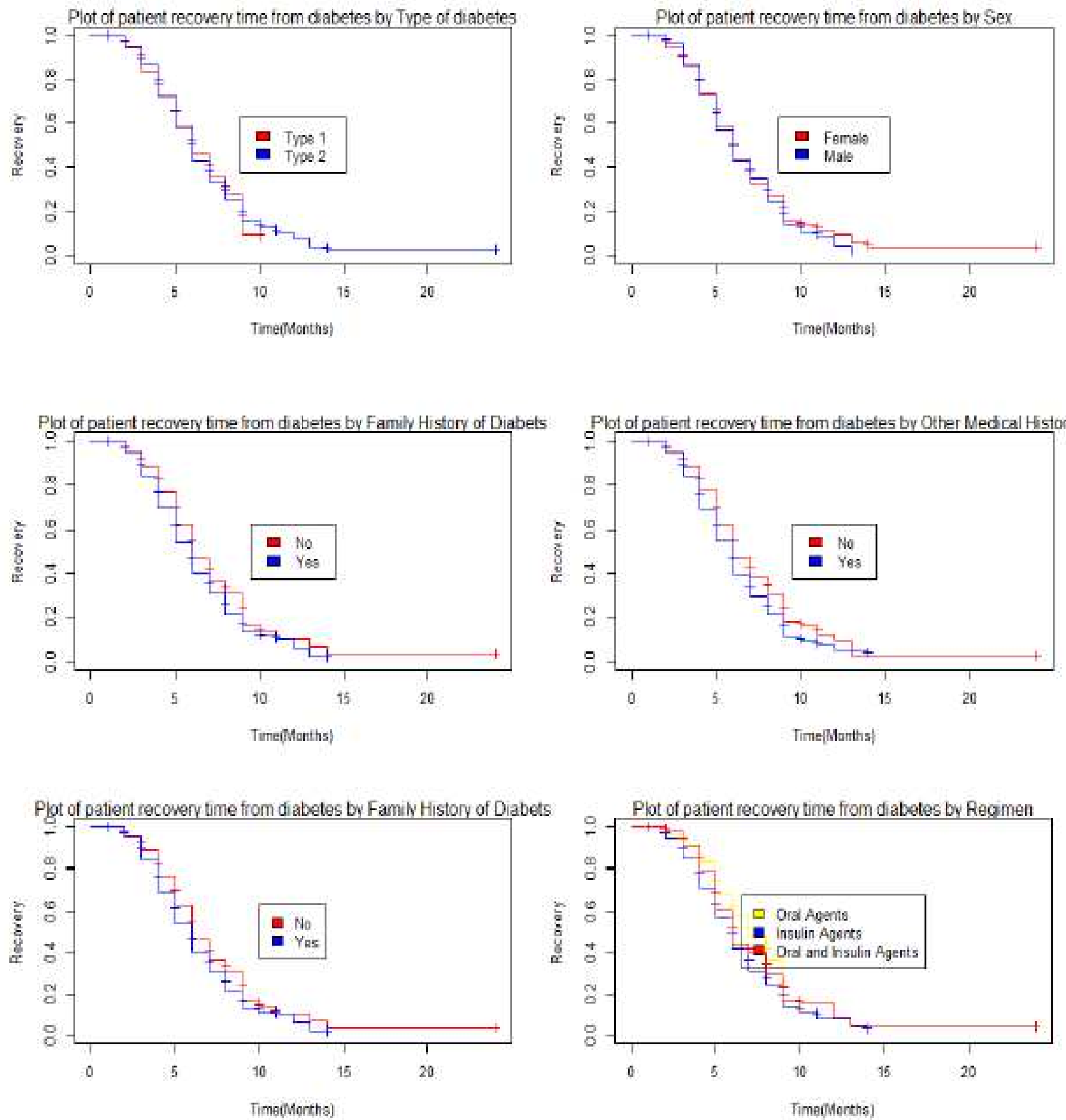

Figure 3: Kaplan-Meier Plot for different variables 


\section{Supplementary Files}

This is a list of supplementary files associated with this preprint. Click to download.

- DataExtructionFormat.docx

- RcodeusedintheAnalysis.txt 